This divergence is only rarely examined, though often discussed. While general practitioners tell colleagues their atrocity stories (my favourite is the one of a general practitioner, summoned for a night call because the baby had swallowed a condom, who was later phoned and told he needn't bother as they had found another one), patients tell their friends their stories of failures to diagnose. But the divergence is normally latent rather than manifest. As Philip Strong describes in his elegant essay on the etiquette of the consultation, "As every ... doctor was overtly competent, so every ... mother was nominally treated as loving, honest, reliable and intelligent: not, of course, capable of passing judgement on medicine, but certainly fulfilling her maternal duty to the child." 9

Parents' views of being "a good mother" can conflict with professional views. ${ }^{10}{ }^{11}$ However, in dealing with the content of health behaviour ("inappropriate" consultations) rather than the context of the visit ( 24 hours a day, seven days a week health surveillance by the mother) there is the risk that a child or a patient may be seen as a "work object," however compassionately dealt with. A recognition of parents' key role in the health care of their children would go beyond Illingworth's textbook advice that doctors do well to attend to parents' views. ${ }^{12}$ Parents are the principal health carers of their children and are in a unique position to take an overall view of their health. This week's qualitative papers on general practice indicate the value of low technology interventions such as listening.

HELEN ROBERTS

Policy and Development Unit, Coordinator of research and development

Barnardo's,

Barkingside,

Essex IG6 1QG

1 Singh S. Self referral to accident and emergency departments: patients' perceptions. $B M \mathcal{F}$ 1988;297:1179-80.

2 Hall DMB, ed. Health for all children: the report of the foint Working Party on Child Health Surveillance. Oxford: Oxford University Press, 1989.

3 Polnay L. Child health surveillance.BMF 1989;299:1351-2.

4 Kai J. Parents' difficulties and information needs in coping with acute illness in preschool children: a qualitative study. $B M \mathcal{F}$ 1996;313:987-90

$5 \mathrm{Kai} J$. What worries patients when their preschool children are acutely ill, and why: a qualitative study. $B M \mathcal{F} 1996 ; 313: 983-6$.

6 Hopton J, Hogg R, McKee I. Patients' accounts of calling the doctor out of hours: a qualitative study of general practice. $B M F$ 1996;313:991-4.

7 Fox R. Training for uncertainty. In: Merton RK, Reader G, Kendall PL, eds. The student physician. Cambridge: Harvard University Press, 1959.

8 Black D. An anthology of false antitheses. London: Nuffield Provincial Hospitals Trust, 1984

9 Strong P. Minor courtesies and macro structures. In: Drew P, Wooton A, eds. Erving Goffman: explaining the interaction order, 1988. Cambridge: Polity, 1988.

10 Cunningham-Burley S. Mothers' beliefs about and perceptions of their children's illnesses. In: Cunningham-Burley S, McKeganey N, eds. Readings in medical sociology. London: Routledge, 1990.

11 Roberts H. Professionals' and parents' perceptions of A and E use in a children's hospital. Sociological Review 1992;40:109-31.

12 Illingworth CM. The diagnosis and primary care of accidents and emergencies in children. Oxford: Blackwell, 1982.

\title{
Primary care in the United States
}

\section{Getting more academic but needs greater cooperation between family physicians and primary care internists}

Primary care is on the up in the United States. Despite the failure of the Clinton health plan, many American politicians now believe what governments know worldwide-that primary care delivered by generalist doctors is the most cost effective way to deliver health care. Of course, primary care means many things in the United States: general internal medicine, paediatrics, and obstetrics, as well as family practice. But its core is the same as anywhere else.

The American Board of Family Practice defines primary care as a highly personalised type of first contact care that is comprehensive, ensures continuity of care and continuing responsibility for individual patients, and coordinates all a patient's health care needs. This sounds like general practice to the European ear. But Americans steer clear of the term because the general internists don't want to be muddled up with the family physicians and the family physicians don't want their broad biopsychosocial approach to be underestimated.

However, semantic scuffles and more serious turf wars among America's primary care doctors could soon be relegated to the past. The professional bodies that represent these doctors are collaborating as never before: developing shared policies and encouraging joint training and research. The American boards of both internal medicine and family practice hope that a more united front might attract more doctors to primary care. ${ }^{1}$ Assuming that Americans want and deserve universal access to high quality health care by the end of the century (an assumption that most policymakers share ${ }^{2}$ ) the nation is going to have to find 35000 more generalists and lose 115000 specialists. $^{3}$

The balance of medical manpower is already shifting. Last year one in four American medical graduates said they intended to work in primary care, compared with only one in seven in 1992. ${ }^{4}$ This may be because medical students now receive much more training in community and primary care and see many more positive role models working as generalists. ${ }^{5}$ Academic units of family practice exist in more than 100 of America's 130 medical schools. And more than 400 family practice residency programmes provide postgraduate clinical training over three years in doctors' offices and community hospitals.

But medical schools wanting to improve their teaching in primary care still have an uphill struggle because they stand to lose money. The amount of federal funding for biomedical research (from the National Institutes of Health) is inversely proportional to the annual number of generalists produced by a medical school. ${ }^{3}$ This is worrying, given that medical schools get nearly a fifth of their funding through research grants. ${ }^{7}$

For this reason, and many others, research in primary care is not an academic luxury. Good, relevant research is essential for diagnosing and treating the diffuse and chronic conditions that present in primary care and don't fit the clinical evidence provided by predominantly hospital based studies. ${ }^{8}$ Research also raises the credibility and reputation of primary care and probably encourages medical students to choose careers in the discipline. ${ }^{6}$

But research is expensive and funding is scarce. So one organisation, the North American Primary Care Research Group (NAPCRG), set up in 1972, is trying to help primary care physicians in the United States and Canada to win big research grants. Through its new family medicine grant generating project, coordinated by Professor David A Katerndahl of the University of Texas at San Antonio, the group links family practice researchers with mentors in 10 universities nationwide. The mentors' remit is to help develop research proposals that will get through strict peer review and stiff competition and join the $10 \%$ that receive major (RO1) grants. In the project's first year, which ended in June, five of the group's ten applications to the National Institutes of Health won RO1 grants; three are still awaiting review.

However, academic primary care needs more than additional money; it also needs to change its culture. At NAPCRG's 23rd annual congress in Houston last November, Professor Bernard Ewigman from the Department of Family 
and Community Medicine at the University of Missouri warned that university departments of primary care are often too bogged down by clinical work and teaching to train and support principal investigators and to allow time and resources for research.

Nevertheless, primary care in America is rapidly becoming a leader rather than a follower, although its internal divisions could hold it back. Family medicine rightly claims to represent the core of American primary care, but its research structure has some catching up to do. The general internists and general paediatricians can claim to lead primary care research and evidence based practice (through bodies like the Society for General Internal Medicine), but they have lagged behind in education by continuing to offer hospital based training programmes. Those who practise primary care need to pool their individual strengths if they are to build a strong and united partnership.

TRISH GROVES General practice editor

$B M F$,

London WC1H 9JR

JOHN ROBERTS

Physician

York Health System Medical Group,

York, Pennsylvania 17403,

USA

5 Campos-Outcalt D, Senf J, Watkins AJ, Bastacky S. The effects of medical school curricula, faculty role models, and biomedical research support on choice of generalist physician careers: a review and quality assessment of the literature. Academic Medicine 1995;70:611-9. 6 Bland CJ, Meurer LN, Maldonado G. Determinants of primary care specialty choice: A nonstatistical meta-analysis of the literature. Academic Medicine 1995;70:620-41. Kimball HR, Young PR. A statement on the generalist physician from the American Boards of
Family Practice and Internal Medicine. $¥ A M A$ 1994;271:315-6.

Starfield B, Simpson L. Primary care as part of US health services reform. $\mathcal{F} A M A$ 1993;269:3136-9.

3 Council on Graduate Medical Education. Recommendation to improve access to health care through physician workload reform. Fourth report to Congress and the Department of Health and Huma Services Secretary. Washington, DC: US Department of Health and Human Services, 1994.

4 Ramsay S. US graduates lured by primary care. Lancet 1995;346:1154.
7 Ganem JL, Krakower JK, Beran RL. Review of US medical school finances, 1992-1993. JAMA 1994;272:705-11.

8 Kendrick T. Prescribing antidepressants in general practice. BMJ 1996; 313:829-30.

\section{Diagnosing death}

\section{Getting it right is vital if opportunities for resuscitation are not to be missed}

Britain's mortality statistics for 1990 report that $23 \%$ of all deaths occurred at home. ${ }^{1}$ This percentage is likely to increase, ${ }^{2}$ and it will be the local general practitioner who is usually summoned to certify death. Furthermore, in the case of sudden death the general practitioner will often arrive when the paramedics are still "on their way" and may have to make the diagnosis without the aid of high tech equipment. However, making a clinical diagnosis of death is rarely mentioned in modern textbooks, although much is written about pronouncing brain death. There is often considerable doubt about the actual moment of death, particularly for those witnessing the process of dying, ${ }^{34}$ as the warmth of the body and the long unnerving intervals between respiratory gasps can be misleading. ${ }^{4}$ Few reliable criteria exist by which the moment of death can be precisely identified. ${ }^{5}{ }^{6}$ Furthermore, attempts to define death depend on the subjective concepts of what constitutes biological life and personhood, and thus at what point the integration of functions of biological life constitute a living human being.

A body's organs and tissues do not die simultaneously, and only certain organs are regarded as crucial to the life of the "whole" person. Technological advances have led to the development of tests to determine the absence of integration between functions of respiration, circulation, and the nervous system. However, it is the sensorimotor potential rather than heartbeat and respiration that has become recognised as defining life, and this has led to a conceptual crisis in diagnosing death. ${ }^{7}$ This blurring of the boundary between life and death has undermined the traditional clinical method, ${ }^{6}$ even though this is the method on which most doctors must rely. For many practitioners, the diagnosis of death has largely "sunk into a commonplace formality" 8 and on occasions, fortunately rare, the diagnosis has been wrong. ${ }^{9}$

Evidently, definitions are complicated. For example, "somatic" or systemic death implies reversible death. Here respiration and cardiac output may have ceased, but a period of lingering vitality exists in which there may be potential for resuscitation. Hopefully, the distinction between somatic death and "molecular" or irreversible death, where the progressive disintegration of the body tissues has started, should be readily apparent to a doctor. ${ }^{10}$
Guidelines would help to ensure accurate diagnosis of death in the community. These would be the same whether death was expected or unexpected. First, a rapid assessment is needed, while taking a history from any attendants, to exclude the need for resuscitation. Initial observation should confirm a deathly pallor (pallor mortis), particularly of the face and lips, and relaxation of the facial muscles leading to drooping of the lower jaw and open staring eyes.

To confidently exclude somatic death, a complete physical examination should be conducted, preferably in private so that the presence of relatives does not inhibit its thoroughness. The examination should exclude central and peripheral circulation through the palpation of the carotid, radial, and femoral arteries. The absence of heart and lung sounds should be determined by auscultation continually for one minute and repeated intermittently over a period of not less than five minutes. ${ }^{11}$ Caution is required as in very corpulent individuals, or conditions such as pericardial effusion, the normal heart sounds may be indistinct. Simultaneously, observations should be made for respiration. Inspection of the eyes is mandatory but not just for fixed and dilated pupils. There is a dry, often cloudy appearance to the cornea, an absence of corneal reflexes, and loss of eyeball tension. ${ }^{10}$ Examination of the fundi may show segmentation of retinal blood columns, referred to by different authors as trucking, palisading, railroading, or boxcars. This is a definite sign of death, although nearly two thirds of dead people do not display this sign. ${ }^{12}$

Indisputable signs that occur some time after death are those of molecular death. These include purpuric death spots (postmortem staining) as a result of hypostasis, which may appear as soon as half an hour after death; the onset of increasing muscle stiffness after three hours and the beginnings of rigor mortis ${ }^{10}$; and decreasing body temperature, which may not be obvious until as long as eight hours from the time of death. ${ }^{10}$

Doctors in doubt about the diagnosis of death should be especially cautious in situations in which a person could seem dead.' Hypothermia, particularly in an elderly person, is perhaps the likeliest of such scenarios. Similarly, anything which causes coma can impair temperature regulation and so lead to hypothermia. Not only may hypothermia cause depres- 